\title{
Article \\ Influence of the Fly Ash Content on the Fresh and Hardened Properties of Alkali-Activated Slag Pastes with Admixtures
}

\author{
María Jimena de Hita (D) and María Criado *(D) \\ Instituto de Ciencias de la Construcción Eduardo Torroja, Spanish National Research Council (CSIC), \\ Serrano Galvache 4, 28033 Madrid, Spain; mariajimena.dehita@ietcc.csic.es \\ * Correspondence: maria.criado@ietcc.csic.es; Tel.: +34-91-30-20-440
}

check for updates

Citation: de Hita, M.J.; Criado, M. Influence of the Fly Ash Content on the Fresh and Hardened Properties of Alkali-Activated Slag Pastes with Admixtures. Materials 2022, 15, 992. https://doi.org/10.3390/ ma15030992

Academic Editor: Maria Bignozzi

Received: 27 December 2021

Accepted: 23 January 2022

Published: 27 January 2022

Publisher's Note: MDPI stays neutral with regard to jurisdictional claims in published maps and institutional affiliations.

Copyright: (C) 2022 by the authors. Licensee MDPI, Basel, Switzerland. This article is an open access article distributed under the terms and conditions of the Creative Commons Attribution (CC BY) license (https:// creativecommons.org/licenses/by/ $4.0 /)$.

\begin{abstract}
A study on the influence of the inclusion of slag or fly ash and five types of superplasticizers on the fresh and hardened properties of alkali-activated cements is presented. Three alkali-activated slag formulations with different fly ash content $(0,15$, and $30 \%)$ in the presence of five admixtures (vinyl copolymer, melamine, and three polycarboxylates with different chain lengths) were assessed for fluidity control and setting adjustment without loss of mechanical properties. Solid sodium metasilicate was used as an alkaline activator. Their fresh and hardened properties were studied through slump, setting time, isothermal calorimetry, mechanical strengths, and porosity tests. The results showed that the increase of fly ash content delayed the reaction and improved workability but reduced compressive strengths. Concerning the admixtures, these maintained fluidity especially for the one based on polycarboxylate with very long chains. The melamine and polycarboxylate with very long chain admixtures did not have a drastic impact on mechanical properties at early ages; even a gain of flexural and compressive strength was noted.
\end{abstract}

Keywords: alkali-activated slag/fly ash; admixtures; workability; setting time; stability; mechanical strengths

\section{Introduction}

Alkali-activated materials can be produced by one of two procedures: the one-part mix system and the two-part mix system. In the one-part or "just add water" system, which is new, both the aluminosilicate precursor and alkaline activator are in their solid state [1,2], which requires the addition of water to act as a cementitious material. In the two-part system, the most commonly used to date, a solid precursor is mixed with a liquid alkaline activator [3-5]. Several problems associated with the liquid alkaline activators have been observed as they are highly corrosive and viscous, making transportation and handling difficult in their operation.

In the past few decades, the production of alkaline-activated blast furnace slag and class F fly ash has been extensively studied. Both these alkali-activated cementitious materials present a series of advantages and disadvantages according to different chemical reactions and curing conditions. Among the main characteristics of alkali-activated slag are high strength, rapid setting, impermeability, and improved fire resistance [6-8], while high-strength, high-heat and acid resistance [9-13] are alkali-activated fly ash features.

However, fly ash requires heat treatment to be activated and set due to its low activity at room temperature. This problem can be overcome by adding slag, boosting the reactivity of the system, and increasing the strength due to the coexistence of alkaline aluminosilicate hydrated gels, usually N-A-S-H with C-A-S-H [14,15]. In addition, a higher slag content as a replacement for the fly ash in the system also favors matrix densification, resulting in a reduced chloride migration rate in concrete [16]. In the case of the alkali-activated slag, the type and the chemical constitution of the alkaline activator strongly affect the reaction kinetics and strength development, leading to workability loss and rapid setting [17]. The 
incorporation of fly ash with a lower percentage of $\mathrm{CaO}$ lengthens the setting time and prevents rapid hardening $[18,19]$.

If these alkali-activated materials are considered as binders for most construction operations [20-24], a selection of chemical admixtures is the best option for fluidity control and setting adjustment without losing mechanical properties. These admixtures are designed for Portland cement and plasticize and fluidize the concrete through an electrostatic or steric mechanism that causes repellency between cement particles [25]. However, their effectiveness in alkali-activated cement is not assured due to the pore solution of these cements with a higher $\mathrm{pH}$ and ionic strength, which poses a prejudice to the stability of admixtures. The first concern is physical stability related to the agglomeration, color change or separation into layers of superplasticizers in the alkaline activator [26]. The second one is chemical stability because the molecular structure of the admixtures changes in highly alkaline activator solutions [26]. In previous studies [27,28], chemical structural changes were observed in some superplasticizers when the $\mathrm{pH}$ of the alkaline medium was up to 13 . Under these conditions, esters and amides underwent alkaline hydrolysis, while the ethers and aromatics were stable.

Few studies have been developed to investigate the properties of fresh alkali-activated slag/fly ash pastes in the presence of chemical admixtures [2,29-34]. If a fixed percentage of slag and fly ash is taken into account, the results obtained by Keulen et al. [29] showed that significantly improved workability and strength development of fly ash/slag $(73.7 / 25)$ concrete were obtained by an increased polycarboxylate admixture content. Alrefaei et al. [30] evaluated the effectiveness of three different types of superplasticizers in a one-part alkali-activated slag/fly ash (50/50) material using anhydrous $\mathrm{Na}_{2} \mathrm{SiO}_{3}$ as the activator. All of them significantly improved the flowability and marginally affected the compressive strength. For a high water/precursor $(\geq 0.36)$, polycarboxylate was effective, while naphthalene performed better as a low water/precursor $(\leq 0.36)$. Oderji et al. [2] focused their work on the investigation of a one-part fly ash/slag $(85 / 15)$ binder cured at room temperature to obtain the best workability with reasonable mechanical strength in the presence of $2 \mathrm{wt} . \%$ of borax, sodium triphosphate, polycarboxylate, sodium gluconate, sodium lignosulphonate, and calcium lignosulphonate. The results revealed that sodium gluconate had lower mechanical strength compared to borax but exhibited comparable workability. Sodium triphosphate had lower workability to borax but exhibited comparable mechanical strength. In addition, both lignosulphonate-based admixtures were quite ineffective since they led to a marked decline in mechanical properties and did not improve workability. Finally, the polycarboxylate had a behavior similar to that of the control mix without admixture.

On the other hand, there are other studies that consider the effect of inclusion of different contents of slag or fly ash, Jang et al. [31] reported that polycarboxylate shows a retarding effect on alkali-activated fly ash/slag pastes $(0 / 100,30 / 70,50 / 50,70 / 30$, and 100/0) with negligible effect on the heat of hydration, and improves workability more significantly than naphthalene. A content of more than $2 \mathrm{wt} . \%$ polycarboxylate positively affected mechanical development before 7 days. Laskar et al. [32] observed that the addition of fly ash $(0,20,30,40$, and $50 \%)$ contributed to achieving satisfactory compressive, workability and bond strength of the geopolymer concrete up to a certain percentage of substitution. Polycarboxylate showed better workability, compressive and bond strength than naphthalene at all dosage levels. A study to examine the effect of dosage of superplasticizers ( 0 to $3 \%$ ) on the rheological properties of alkali-activated fly ash and slag $(0 / 100,25 / 50,50 / 50,75 / 25,100 / 0)$ composites with varying alkali/binder ratios was conducted by Namitha et al. [33]. The setting time increased marginally with the dosage of polycarboxylate. The use of naphthalene with an increase in a/b ratio was not very effective in prolonging the setting time of alkali-activated pastes. Moreover, Raju et al. [34] investigated the effect of the inclusion of slag and the type and dosage of superplasticizers on the fresh properties of alkali-activated fly ash paste $(0,25,50,75,100)$. An increase in slag content and a decrease in alkali content reduced setting time and workability. Naphthalene 
performed better than polycarboxylate in the mini-slump test for all the mixes. In the case of the setting time test, naphthalene showed more effectiveness at retarding the set for the $100 \%$ slag paste.

This study was carried out within the framework of the IRINEMA project (Immobilization of Nuclear grade Ion Resins in Alkali-activated Materials, 2019-T1/AMB-13672). The aim of it was to find an alkali-activated material to replace the Portland-based cement currently used to immobilize nuclear waste. Slag and ash proportions were chosen as a starting point for the formulation currently used in Spain for this purpose, which is approximately $70 \%$ OPC-30\% FA. It was decided to substitute the OPC for BFS to carry out comparative studies (70\% BFS) and to evaluate the behaviour of a total substitution by slag (100\% BFS) and an intermediate value to evaluate possible trends (85\% BFS).

To avoid the flash-setting problem and improve fluidity, three alkali-activated slag formulations with different fly ash content, together with the presence of five admixtures (vinyl copolymer, melamine, and three polycarboxylates with different chain lengths), were developed. Their fresh and hardened properties were studied through slump, setting time, isothermal calorimetry, mechanical strength, and porosity tests. To carry out this study, new commercial admixtures were evaluated: a vinyl copolymer with ester groups in its structure and a polycarboxylate, PC3, the formation chemistry and structure of which are different from traditional polycarboxylate ether admixtures. Since they could perform better than commercial admixtures designed for Portland cement in highly alkaline media and solve their denaturation problem. Moreover, the addition of admixtures was carried out in two stages to prevent these chemical structural changes and maintain fluidifying properties.

\section{Materials and Methods}

\subsection{Materials}

In this study, Spanish blast-furnace slag (BFS, Calumite Ibérica) and fly ash from a Spanish power plant (FA) were waste material used as binder material. The as-received slag was milled in a mechanical ball mill so that $96 \%$ of the particles would be smaller than $45 \mu \mathrm{m}$ to avoid coarse granules and increase reactivity while conducting the tests. The chemical composition of two raw materials was determined by X-ray fluorescence spectroscopy (XRF, S8 Tiger Bruker), see Table 1. The specific surface area by laser granulometry (MASTERSIZER S) and average particle sizes by BET method [35] (ASAP 2010, Micrometrics Instrument Corporation, Norcross, GA, USA) of the slag and fly ash were 1154 and $2023 \mathrm{~m}^{2} / \mathrm{kg}$ and 3.8 and $38.4 \mu \mathrm{m}$, respectively.

Table 1. Chemical composition of BFS and FA used in this study.

\begin{tabular}{|c|c|c|c|c|c|c|c|c|c|c|c|}
\hline Oxides (wt.\%) & $\mathrm{CaO}$ & $\mathrm{SiO}_{2}$ & $\mathrm{Al}_{2} \mathrm{O}_{3}$ & MgO & $\mathrm{SO}_{3}$ & $\mathrm{TiO}_{2}$ & $\mathrm{Fe}_{2} \mathrm{O}_{3}$ & $\mathrm{~K}_{2} \mathrm{O}$ & $\mathrm{Na}_{2} \mathrm{O}$ & Others & L.O.I * \\
\hline BFS & 45.7 & 32.3 & 9.6 & 7.1 & 1.6 & 0.9 & 0.5 & 0.5 & 0.3 & 0.5 & 0.95 \\
\hline FA & 4.8 & 42.4 & 27.0 & 0.8 & 1.4 & 1.1 & 18.4 & 1.5 & 0.5 & 0.5 & 1.60 \\
\hline
\end{tabular}

${ }^{*}$ L.O.I am the loss on ignition at $1000^{\circ} \mathrm{C}$.

The alkaline solution was sodium metasilicate powder $\left(\mathrm{Na}_{2} \mathrm{SiO}_{3}\right.$, Sigma-Aldrich, Barcelona, Spain) with a concentration of $7 \mathrm{wt}$ \% by mass of binder [36]. Sodium silicate was chosen as an alkaline activator in this work because previous studies [37-39] reported that its use lead to the formation of alkali-activated material with good mechanical and durability performance. This activator is solid and the solution can be produced in situ to avoid transportation problems in the operation. The liquid-to-solid (anhydrous slag/fly ash + anhydrous sodium metasilicate) ratio was 0.45 .

The admixtures that were used in this study were vinyl copolymer (V), melamine (M) and three polycarboxylates (PC1, PC2 and PC3) of different chain lengths. All of them were supplied by Sika Spain. The characteristics and dosage of the admixtures are shown in Table 2. 
Table 2. Characteristics and dosage of the five chemical admixtures.

\begin{tabular}{cccccc}
\hline Admixtures & $\mathbf{V}$ & $\mathbf{M}$ & PC1 & PC2 & PC3 \\
\hline Structure & $\begin{array}{c}\text { Sulphonate } \\
\text { groups and } \\
\text { ester }\end{array}$ & $\begin{array}{c}\text { Sulphonate } \\
\text { groups }\end{array}$ & $\begin{array}{c}\text { Comb-like structure } \\
\text { (backbone and short } \\
\text { side chain length) }\end{array}$ & $\begin{array}{c}\text { Comb-like structure } \\
\text { (backbone and long } \\
\text { side chain length) }\end{array}$ & $\begin{array}{c}\text { Structure with very } \\
\text { long chain length }\end{array}$ \\
\hline Action mechanism & $\begin{array}{c}\text { Mainly } \\
\text { electrostatic } \\
\text { repulsion }\end{array}$ & $\begin{array}{c}\text { Electrostatic } \\
\text { repulsion }\end{array}$ & $\begin{array}{c}\text { Mainly steric } \\
\text { hindrance }\end{array}$ & $\begin{array}{c}\text { Mainly steric } \\
\text { hindrance }\end{array}$ & $\begin{array}{c}\text { Mainly steric } \\
\text { hindrance }\end{array}$ \\
\hline Dosage (\% binder) & 1.00 & 1.20 & 1.00 & 1.25 & 1.10 \\
\hline
\end{tabular}

\subsection{Preparation of the Alkali-Activated Pastes and Mortars}

Three formulations of blend pastes and mortars were made with slag/fly ash in the ratio of 100/0 (referred to as 100\% BFS), 85/15 (referred to as 85\% BFS) and 70/30 (referred to as $70 \%$ BFS) by mass and then activated with sodium metasilicate. To ensure the homogeneity of these mixtures, they were introduced into a turbula for $1 \mathrm{~h}$, and their activation was carried out in two stages. Prior to the activation process, the admixture was pre-dissolved in half the water to avoid denaturation when it came in contact with the activator, whereas the activator was dissolved in the other half of the water under magnetic stirring. In the first stage, the dissolved admixture was incorporated into the blend and the paste was mixed for $2 \mathrm{~min}$ at $500 \mathrm{rpm}$. In the second one, the activator solution was added and mixed for another $2 \mathrm{~min}$ at $500 \mathrm{rpm}$. To produce the mortar specimens $\left(4 \times 4 \times 16 \mathrm{~cm}^{3}\right)$, the sand/binder ratio was held at 3 . A standardized, evenly graded siliceous sand was employed $\left(\mathrm{SiO}_{2}\right.$ content of $\left.99 \%\right)$. Mortars were sealed with cling film and cured at $20 \pm 2{ }^{\circ} \mathrm{C}$ for 2 and 28 days, after which they were subjected to different tests.

\subsection{Testing Procedure}

Several tests were conducted to determine the fresh properties of the alkali-activated slag/fly ash pastes and analyse the admixture stability in the alkaline solution.

Mini-slump tests consisted of measuring the expansion (diameters) of materials on a flat methylmethacrylate plate at zero time, the time of their mixing, and at $30 \mathrm{~min}$ intervals for $2 \mathrm{~h}$ in this study. The paste was introduced into a truncated conical mould $\left(19 \times 37.5 \times 57.5 \mathrm{~cm}^{3}\right)$ and after one minute, the mould was lifted in the vertical direction and the diameter of the spread pat was measured using a caliper [40].

The setting time test consists of the periodic introduction of a standard needle into a cementitious material, and after analysing its specific resistance to penetration, the initial and final times of the setting period were determined according to European Standard UNE-EN 196-3 [41]. An automatic Vicat Needle (AUTO-VICAT, Ibertest, Madrid, Spain) was employed, and the tests were carried out on the same formulations that were used in the mini-slump tests.

Stability tests were conducted on the five admixtures in the sodium metasilicate solution ( $\mathrm{pH}=13.4)$ using Fourier transform infrared spectroscopy (FTIR, Thermo Scientific Nicolet 6700, Waltham, MA, USA), to ascertain how their chemical structures had been affected by a highly alkaline medium. The alkaline solution-to-admixture ratio was held at 1. The mixtures were placed in an oven at $120{ }^{\circ} \mathrm{C}$ for $24 \mathrm{~h}$ to remove excess water and then put into a plastic bottle at room temperature for $24 \mathrm{~h}$ to achieve total drying. $\mathrm{KBr}$ pellets ( $200 \mathrm{mg}$ of $\mathrm{KBr}$ and $0.5 \mathrm{mg}$ of admixture) were used to record the spectra. Spectral analysis was performed over a $4000-400 \mathrm{~cm}^{-1}$ range at a resolution of $4 \mathrm{~cm}^{-1}$ (64 scans).

Subsequently, the two most effective admixtures were selected to continue with a more in-depth study of the fresh state through isothermal calorimetry and the solid state through mechanical strengths and porosity. 
The evolution of reaction kinetics was monitored using a TAM Air isothermal calorimeter at $25{ }^{\circ} \mathrm{C}$. The fresh pastes were performed externally and manually ( $2 \mathrm{~min}$ ) and then $5 \mathrm{~g}$ of each paste was transferred immediately into the calorimeter ampoule to record the heat flow. The experiments were conducted during the first 5 days after mixing and all values of the heat release rate were normalised by the total mass of paste analysed.

Mechanical strengths, flexural and compressive, at 2 and 28 days were determined using an Ibertest (Autotest-200/10 - SW) testing frame according to European standard UNE-EN 196-1 [42].

The pore size distribution and pore volume of the mortars at 28 days were analyzed using Micrometrics Autopore IV 9500 porosimeter. The pore diameter was derived using Washburn's law: $\mathrm{D}=(-4 \cos \theta) \gamma / \mathrm{P}$, where $\mathrm{D}$ is the pore diameter $(\mu \mathrm{m}) ; \theta$ is the contact angle between the fluid and the pore mouth $\left(141.3^{\circ}\right) ; \gamma$ the surface tension of the fluid $(485 \mathrm{~N} / \mathrm{m})$; and $\mathrm{P}$ is the applied pressure to fill the pore with mercury (MPa). The maximum pressure applied was $227 \mathrm{MPa}$.

\section{Results and Discussion}

\subsection{Influence of the Fly Ash Content on the Fresh Properties of Alkali-Activated Pastes with Admixtures}

Initially, slump and setting time tests were conducted to determine the fresh properties of the alkali-activated slag/fly ash pastes and the influence exerted by the fly ash content and type of admixtures (vinyl copolymer (V), melamine (M) and three polycarboxylates (PC1, PC2 and PC3) in these parameters. Subsequently, a stability study of the admixtures was carried out to explain the behaviour developed by them in this highly alkaline medium.

\subsubsection{Setting Time}

Figure 1 shows the variation in initial and final setting times of alkali-activated slag/fly ash mixtures with variation in fly ash content and chemical admixture. The setting time of the $100 \%$ BFS sample was an initial time of $9.8 \mathrm{~h}$ and a final time of $11.8 \mathrm{~h}$, while those of the other samples were delayed: $10 \mathrm{~h}$ and $13.7 \mathrm{~h}$ for $85 \%$ BFS and $19 \mathrm{~h}$ and $27.3 \mathrm{~h}$ for $70 \%$ BFS. A higher proportion of fly ash in the alkali-activated slag/fly ash mixtures led to a slower setting due to the lower reactivity of the ash. The content of reactive $\mathrm{CaO}$, the main chemical component of slag, decreased with the higher addition of the fly ash, leading to a lower amount of dissolved $\mathrm{Ca}^{2+}$ ions in the medium and a deceleration of the activation reaction $[19,43,44]$. Thus, the decelerated formation of C-A-S-H gel may lengthen the setting time of alkali-activated slag/fly ash pastes. The setting time of $100 \%$ BFS was directly related to the formation of calcium silicate hydrate $(\mathrm{C}-\mathrm{S}-\mathrm{H})$ gel, but when the ash content was increased in the $85 \%$ BFS and $70 \%$ BFS samples, C-S-H gel also with sodium aluminosilicate hydrate gel (N-A-S-H) was formed [15].

In addition, Figure 1 shows the effect of different admixtures, vinyl copolymer (V), melamine (M) and three polycarboxylates (PC1, PC2 and PC3), on the initial and final setting time of the $100 \%, 85 \%$ and $70 \%$ BFS samples activated with sodium silicate. In the case of $100 \%$ BFS pastes, the presence of admixtures affected the setting times differently, PC1 accelerated the initial setting time by nearly $80 \mathrm{~min}$, while PC2 had the opposite effect: retarding it by $50 \mathrm{~min}$. However, the final sets were longer in all cases. In the case of $85 \%$ BFS pastes, the admixtures based on melamine and the three polycarboxylates retarded the initial setting, especially PC1. For these two admixtures, M and PC1, the final setting time was prolonged by 180 and $230 \mathrm{~min}$, respectively. In the case of the $70 \%$ BFS pastes, the admixtures had no significant effect on the initial setting time, but PC1 lengthened the final set by $400 \mathrm{~min}$, and, for its part, PC2 accelerated it by $190 \mathrm{~min}$. 


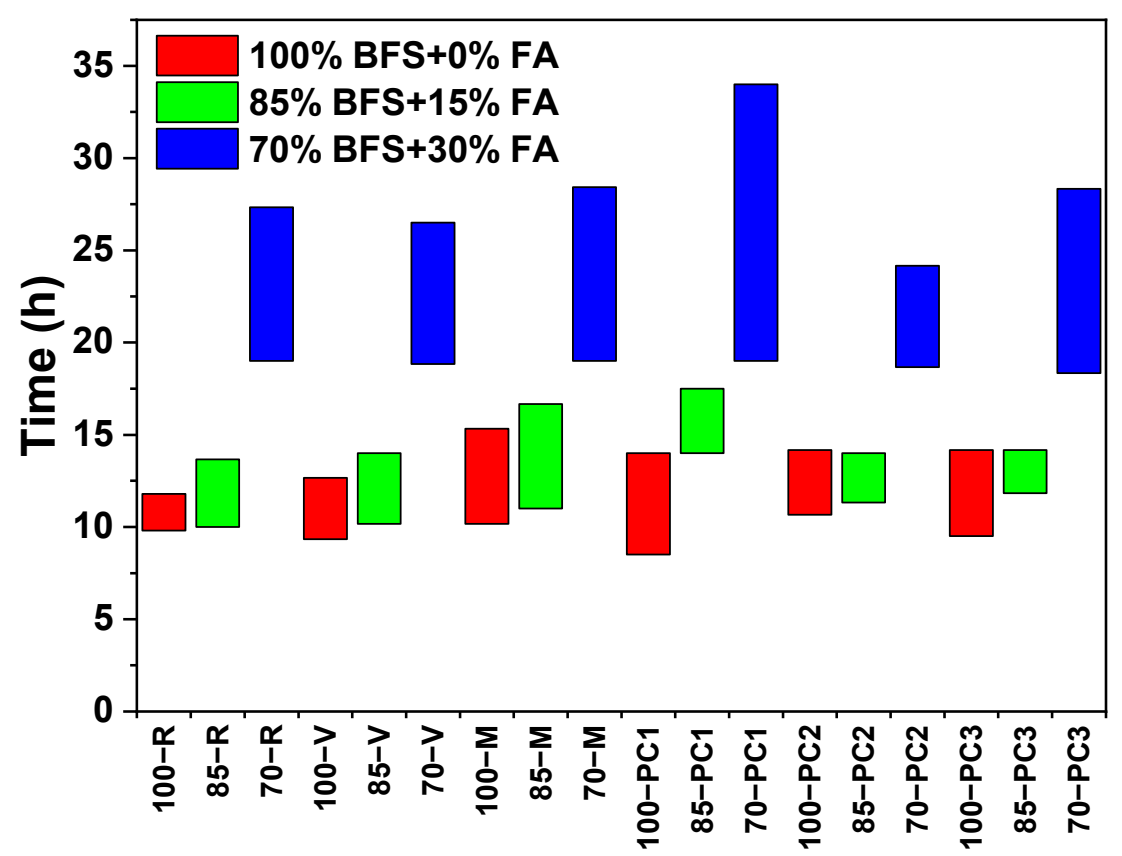

Figure 1. Setting time of different alkali-activated slag/fly ash pastes as a function of BFS/FA ratio and admixture.

\subsubsection{Mini-Slump}

The alkaline activation of the three slag/fly ash mixtures with sodium metasilicate showed good workability at the first moment $(0 \mathrm{~min})$ as is reported in Figure 2. An increase in the replacement of fly ash implied higher slump values. The smooth spherical shape of the ash was a determining factor in this improvement of workability [32], which was studied at 30,60, 90, and $120 \mathrm{~min}$. A decrease in slump values over time was observed in the three formulations. For the $100 \%$ BFS mixture, the slump value was reduced around $40 \%$ at $120 \mathrm{~min}$, while these reductions were lower than $20 \%$ for $85 \%$ BFS and $70 \%$ BFS. Therefore, the rate of decrease in a slump over time decreased with the higher amount of fly ash due to the slower setting of fly ash compared to slag [45].

In Figure 2 results of the mini-slump tests of the alkali-activated slag/fly ash pastes with admixtures are also shown. In the $100 \%$ BFS sample, a clear improvement in the initial flow diameter was observed for $\mathrm{V}$ and PC3 admixtures. However, important retention of the slump between 0 and 120 min took place for $\mathrm{V}$, indicating a possible chemical change in the alkaline solution, while PC3 presented flow loss during the first $30 \mathrm{~min}$ and then these values were maintained. On the other hand, $M$ showed a slump value similar to that of the pastes without admixture in the first moments and retained its flowability for a longer duration, achieving the highest slump value. In the presence of admixtures, the flow of the $85 \%$ BFS paste improved at beginning of the test, except for $V$ that was comparable to the slump for the control paste. The admixture based on melamine and PC3 improved the workability of the three alkali-activated mixes more efficiently during the full $120 \mathrm{~min}$ that the test lasted. According to the results, in the $70 \%$ BFS pastes, an improvement in the initial flow diameter was observed for all admixtures except for PC2, and a small reduction in the rate of flow loss with time was observed with the incorporation of all of them. PC3 displayed the highest rise in flowability. 

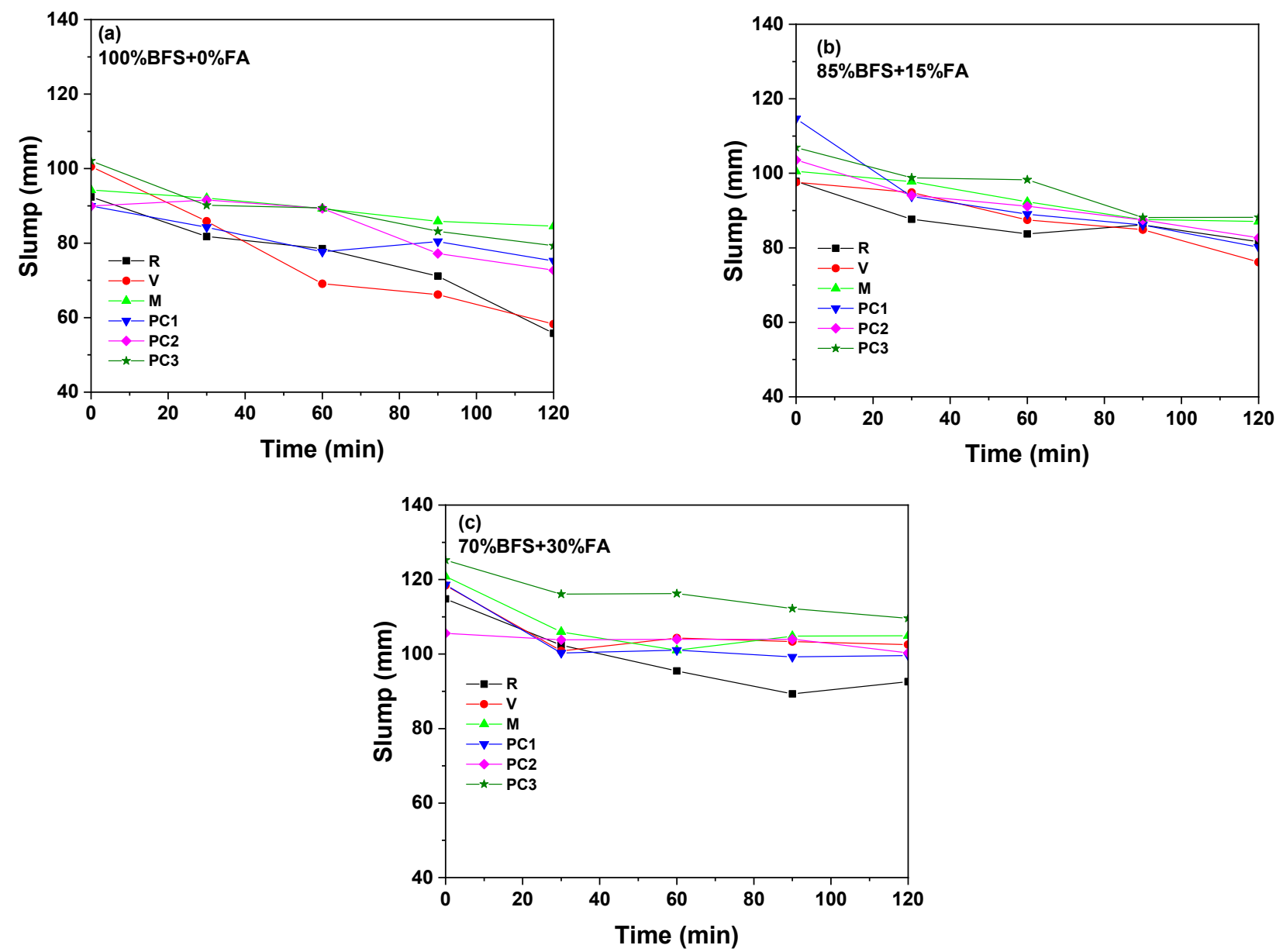

Figure 2. Evolution of the slump values with time for different binder proportions and admixtures. (a) $100 \%$ BFS + 0\% FA, (b) $85 \%$ BFS $+15 \%$ FA, and (c) $70 \%$ BFS + 30\% FA.

The nature of the admixture played a significant role in controlling the workability of the mixes. While the vinyl copolymer had no impact on paste slump and setting time, melamine-based and polycarboxylate (PC3) admixtures increased the workability of fresh pastes in this high alkaline media and even retarded the setting. The addition of melaminebased admixtures, which contain the sulphonate group, implied adhesion to the slag or ash grains, giving the grain a negative electrical charge. The different grains were repelled by electrostatic repulsion, contributing to the release of the liquid component trapped in the flocs. It favoured the mobility of particles, improved the workability, and delayed the setting. In the case of PC3, the electrostatic repulsion was due to the absorption by the carboxyl group, but the presence of long and voluminous chains due to ethylene oxide $\left(-\mathrm{CH}_{2} \mathrm{CH}_{2} \mathrm{O}-\right)$ also allowed the separation of the grains by steric repulsion. This kept the particles sterically at distance, enhancing the mixture workability.

These variations in the effects of the admixture on the setting time and slump could be attributed to their different stability behaviours in the high-alkali media $[28,30,46]$.

\subsubsection{Stability of Admixtures}

The stability of the five admixtures (V, M, PC1, PC2 and PC3) in a sodium silicate medium for $24 \mathrm{~h}$ was studied by FTIR. Their infrared spectra are given in Figure 3 . The absorption peaks at around 3410 and $1640 \mathrm{~cm}^{-1}$ in all the spectra were associated with the stretching and deformation vibration of the water molecules. 

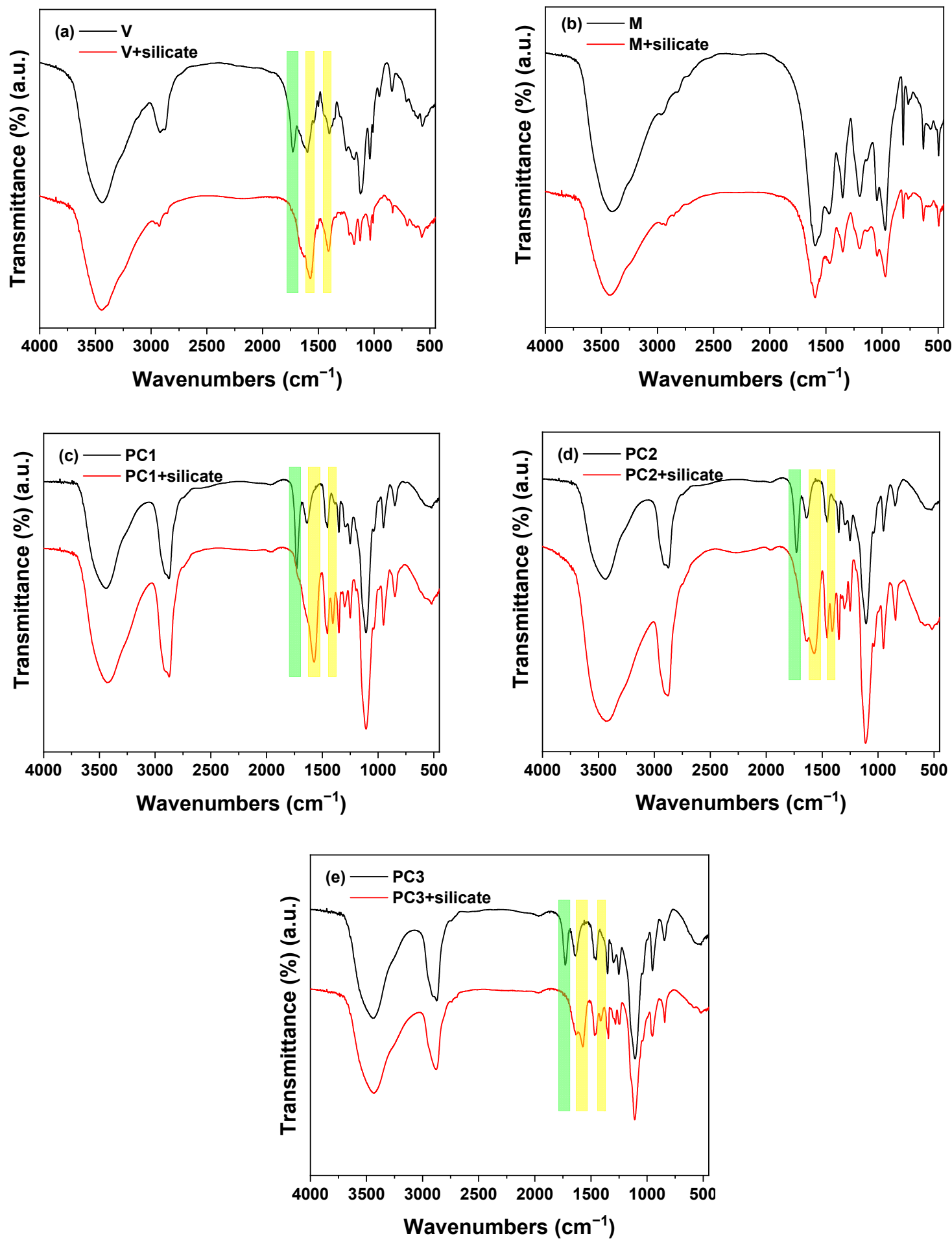

Figure 3. Infrared spectra of the five admixtures in the original state and sodium silicate medium: (a) V, (b) M, (c) PC1, (d) PC2, and (e) PC3. Green: a missing band; yellow: a new band.

The FTIR spectra show that the chemical structure of all admixtures was modified when they were kept in a sodium silicate solution except for the melamine-based. The characteristic vibration bands of the vinyl copolymer (V) admixture appeared at 3438, 1600, and $702 \mathrm{~cm}^{-1}$ corresponding to the vibration of the $\mathrm{N}-\mathrm{H}$ bond of the amine, at $1722 \mathrm{~cm}^{-1}$ corresponding to the vibration of the $\mathrm{C}=\mathrm{O}$ bond of the carboxylic acid, and at 1183 and $1040 \mathrm{~cm}^{-1}$ corresponding to the vibration of the $\mathrm{SO}_{3}{ }^{-}$groups [27]. When $\mathrm{V}$ was kept in the alkaline solution, the band at $1722 \mathrm{~cm}^{-1}$ disappeared, while two new bands were 
observed at 1568 and $1411 \mathrm{~cm}^{-1}$ that were associated with the vibration of carboxylate groups $\left(\mathrm{COO}^{-}\right)$. This resulted from the alkaline hydrolysis of the amide that formed a part of this admixture to give rise to an amine that contained the sulphonate group and the carboxylate salt. These structural changes in the vinyl copolymer in the highly alkaline solutions ( $\mathrm{pH}>13$ ) were previously observed by Palacios et al. [27], which could explain its lower superplasticising effect in the three formulations.

The FTIR spectrum of melamine (M) derivate showed four characteristics bands caused by the vibrations of the $\mathrm{N}-\mathrm{H}$ bond: in the amine $\left(1600 \mathrm{~cm}^{-1}\right)$; the $\mathrm{C}-\mathrm{H}$ bond $\left(1470 \mathrm{~cm}^{-1}\right)$ in the $\mathrm{CH}_{2}$ adjacent to a heteroatom; and the $\mathrm{S}-\mathrm{O}$ bond $\left(1190\right.$ and $\left.1030 \mathrm{~cm}^{-1}\right)$ in the sulphonate groups [30]. When this admixture was kept in the sodium silicate solution, its chemical formulations showed no structural alteration, which justified their good performance as superplasticizers: see Figure 2.

Finally, the adsorption bands at 1730,1467 , and $1350 \mathrm{~cm}^{-1}$ in the polycarboxylate ( $\mathrm{PC} 1$, PC2 and PC3) admixtures belonging to the vibrations of the $\mathrm{C}=\mathrm{O},=\mathrm{CH}_{2}$ and $-\mathrm{CH}_{3}$ groups, respectively $[28,30,47,48]$. In the sodium silicate solution, PC1, PC2 and PC3 admixtures underwent structural changes, which was deduced from the absence of a band at $1730 \mathrm{~cm}^{-1}$ and the detection of two bands around 1574 and $1410 \mathrm{~cm}^{-1}$ associated with the carboxylate groups $\left(\mathrm{COO}^{-}\right)$. These alterations in their structures were due to the alkaline hydrolysis of these admixtures in highly alkaline media, where the ester groups gave rise to the respective ethers and carboxylate salts [27]. In PC1 and PC2, the steric hindrance from these ether chains was practically non-existent. The main chain with the carboxylate groups was adsorbed onto the surface of the slag and fly ash particles, while the lateral chains with ethers broke away from the main chain. However, PC3 had a different, non-comb, structure that presented long chains, and their steric effect may explain why such an admixture worked more efficiently relative to PC1 and PC2.

\subsection{Effect of M and PC3 on the Reaction Kinetic and Hardened Properties of Alkali-Activated Slag/Fly Ash Mixtures}

In light of the results, the melamine-based and polycarboxylate with long-chain admixtures resulted in the best dispersive and fluidifying properties over time for the three formulations. For this reason, a study using isothermal calorimetry was carried out to evaluate the kinetics of the reaction of the $100 \%$ BFS, $85 \%$ BFS and $70 \%$ BFS pastes with $\mathrm{M}$ and PC3. The mechanical strengths were also determined at 2 and 28 days.

\subsubsection{Isothermal Conduction Calorimetry}

The rate of heat evolution and cumulative heat evolution of alkali-activated slag/fly ash pastes in the absence and presence of $\mathrm{M}$ and $\mathrm{PC} 3$ admixtures within the first 5 days is given in Figure 4. The heat release curves (Figure 4a) exhibited a pre-induction period (first peak) during the first hour of reaction. It corresponded to the wetting and dissolution of the raw materials, especially slag, and also partly due to the coagulation of the resulting dissolved silicate and aluminate units and their interactions with $\mathrm{Ca}$ and $\mathrm{Na}[36,43,49]$. The peak was followed by an induction period with a low heat flow and reduced reaction. The new reaction products grew rapidly, and the surface of anhydrous slag particles was covered by a layer of these products. Therefore, the amount of available alkalis for slag dissolution was limited and the heat flow was reduced [50]. In this study, its duration was strongly dependent on both the binder composition (the nature and the reactivity of the raw materials) and the nature of the admixture. After this period, an intense peak (constituted by acceleration and deceleration periods) was observed and associated with nucleation, growth and precipitation of reaction products, $\mathrm{C}-\mathrm{A}-\mathrm{S}-\mathrm{H}$ and $\mathrm{N}-\mathrm{A}-\mathrm{S}-\mathrm{H}$ gels. The formation of these gels was the result of a condensation reaction between the silicate and the aluminate species and silicate present in the alkaline activator [36,43]. 
(a)

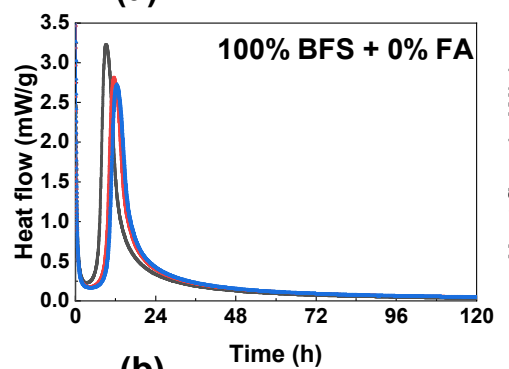

(b)

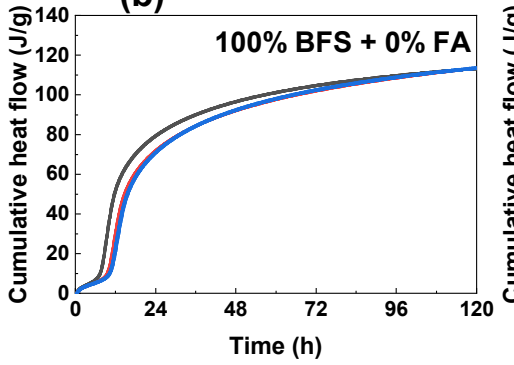

$\longrightarrow \mathbf{R} \leadsto \mathbf{M} \longrightarrow \mathbf{P C 3}$
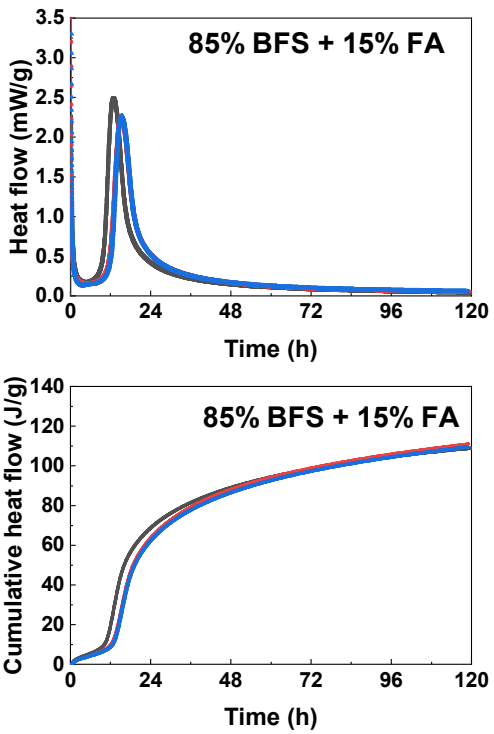
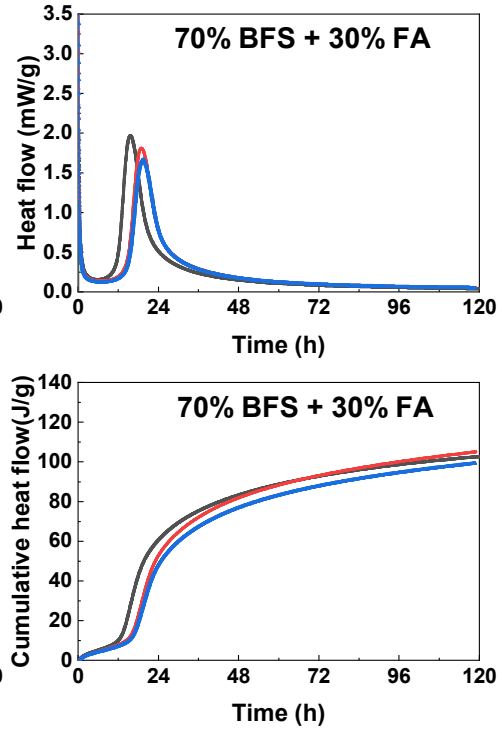

Figure 4. (a) Heat flow and (b) cumulative heat flow of the alkali-activated slag/fly ash pastes in the absence and presence of M and PC3 admixtures within the first 5 days.

After the first heat-evolution peak, all mixes (100\% BFS, 85\% BFS and 70\% BFS) exhibited an induction period that finished about 4,6 , and $8 \mathrm{~h}$ before the acceleration/deceleration peak, respectively. The elongation of the induction time was associated with the low reactivity of the fly ash. It can act as a nucleation site for the reaction products because it has a negative contribution to the further reaction between slag grains and alkalis. In addition, a long time was required to reach a critical ionic species concentration in solution to form reaction products.

The acceleration/deceleration peak appeared at around $9.3 \mathrm{~h}$ for the sample with $100 \%$ of the slag, this peak shifted to longer times with broader and lower intensities as the ash amount increased. When the samples contained $15 \%$ or $30 \%$ of fly ash, the acceleration peak was delayed at $13 \mathrm{~h}$ and $15.7 \mathrm{~h}$ and the peak height decreased by nearly $24 \%$ and $40 \%$ respectively. These differences in the second peak were mainly associated with the reduction of total slag content resulting in a smaller heat release rate and moderate reaction of ash at ambient temperature.

The calorimetric curves also showed that the presence of admixtures retarded the acceleration/deceleration peak and decreased its intensity. In the 100\% BFS sample, the longest delay was induced by PC3, but in the other samples, 85\% and 70\% of slag, the signal had identical position and intensity. M and PC3 admixtures were adsorbed onto the slag and fly ash grains and exerted their superplasticiser function. Therefore, the presence of an admixture and a greater amount of fly ash retarded the initial alkaline activation. However, the nature of the admixtures did not seem to have a significant effect on the reaction kinetic at least in $85 \%$ and $70 \%$ BFS formulations.

The shape of the calorimetric curves in the presence of admixtures was characteristic of alkali-activated slag/fly ash cements, with the main signal associated with the precipitation of the reaction products [31].

The cumulative heat release of the alkali-activated slag/fly ash pastes within the first $120 \mathrm{~h}$ of reaction is shown in Figure $4 \mathrm{~b}$. The two rising portions depicted the heat release contribution due to the wetting and dissolution of slag and the acceleration phase of the reaction, respectively [51]. The relatively flatter region between these two rises corresponds to the induction period.

The cumulative heats were $113 \mathrm{~J} / \mathrm{g}, 109 \mathrm{~J} / \mathrm{g}$ and $103 \mathrm{~J} / \mathrm{g}$ for the $100 \% \mathrm{BFS}, 85 \%$ BFS and $70 \%$ BFS samples respectively at 5 days. Samples with a higher slag percentage exhibited 
higher total heat of reaction, indicating again that ash presented lower reactivity than slag under ambient temperature and that the alkaline activation occurred later.

In the first moments, the inclusion of $\mathrm{M}$ and $\mathrm{PC} 3$ decreased the activation heat in the three formulations. Their presence dispersed the flocs, retarding the precipitation of the reaction products and decreasing the heat release. However, eventually, around $48 \mathrm{~h}$, the cumulative heat raised became quite similar to that obtained for their respective reference samples. The nature of the admixtures only had a slight influence on the total heats in the $70 \%$ BFS sample, where their values were $99 \mathrm{~J} / \mathrm{g}$ and $105 \mathrm{~J} / \mathrm{g}$ for M and PC3, respectively, at 5 days.

\subsubsection{Mechanical Strengths}

Mechanical strengths for the three formulations with $\mathrm{M}$ and PC3 admixtures at 2 and 28 days are reported in Figure 5. The flexural strengths at 2 and 28 days of the three formulations were in the range of 4.9-6.8 $\mathrm{MPa}$ and 8.9-10.6 MPa respectively, but these values decreased with the replacement of slag, see Figure $5 \mathrm{a}$. This same trend is observed in Figure $5 b$ for the compressive strengths, but the differences between the three alkaliactivated slag/fly ash mortars were more marked at both ages. As the slag percentage in the formulation decreased, a lower calcium content was provided to the medium and lower precipitation of the $\mathrm{C}-\mathrm{A}-\mathrm{S}-\mathrm{H}$ gel took place. In addition, the reaction between $\mathrm{Ca}^{2+}$ dissolving from slag grains and silicate anions from the alkaline activators also played an important role in the setting and calorimetry in these systems, as previously observed in Figures 1 and 4. A driving force was provided by the formation of the gel to accelerate the chemical reaction leading to larger strength of alkali-activated binders cured at room temperature $[5,45]$.
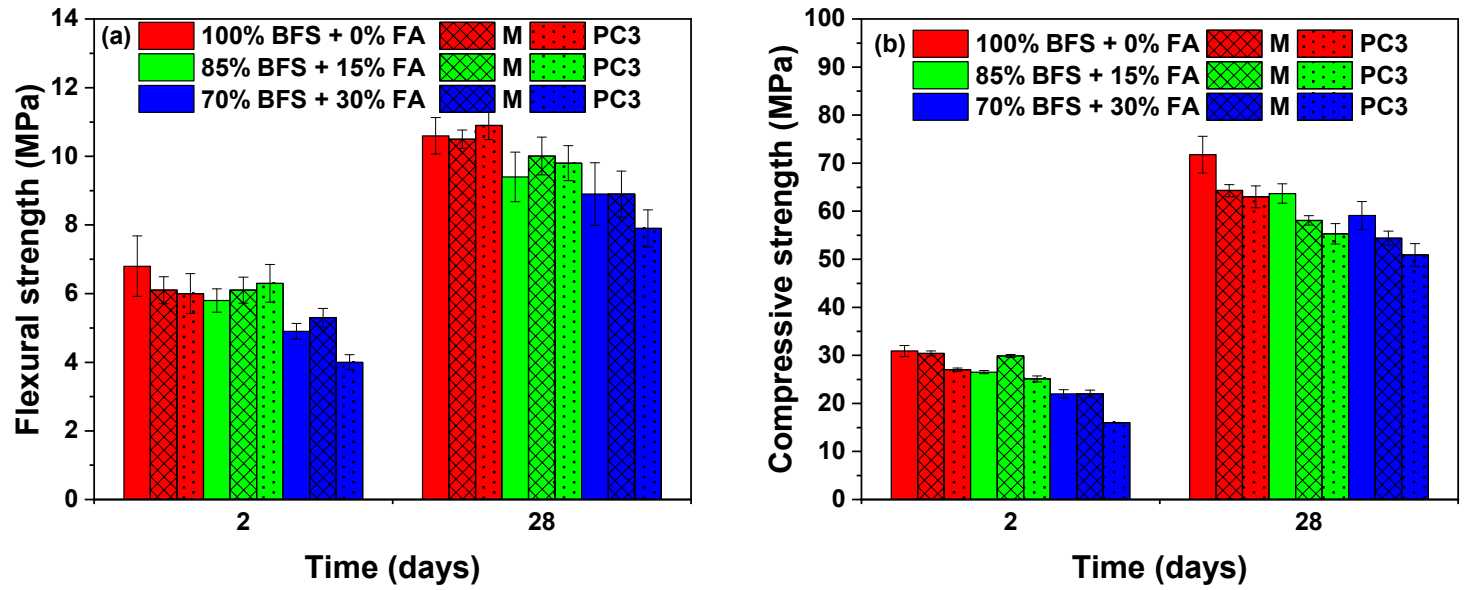

Figure 5. (a) Flexural and (b) compressive strengths of different binder proportions in the absence and presence of M and PC3 admixtures at 2 and 28 days.

As can also generally be seen from Figure 5a, the addition of M and PC3 led to small modifications in flexural strengths at 2 and 28 days independent of the composition of the alkali-activated slag/fly ashes formulations and even slightly increased these values, except for the 70\% BFS sample, where the presence of PC3 attained a lower strength. Therefore, a higher percentage of fly ash and an admixture with high long chains exerting steric repulsion led to a clear loss of mechanical properties.

On the other hand, the effect of the admixtures on compressive strength is shown in Figure 5b. At 2 days, two different behaviours were observed according to the nature of the admixture. For PC3, the compressive values of the three formulations decreased, while for $\mathrm{M}$ they were maintained or increased. This behaviour was attributed to the good dispersion of the slag and/or fly ash particles with an improvement in the mixture workability, thereby obtaining dense and homogeneous mortars [29]. 
However, both types of admixtures negatively affected the compressive strength of the three samples about the control specimens without admixture in the long term, 28 days. In the $100 \%$ BFS samples, the drops in compressive strength were $12 \%$ and $14 \%$ for $\mathrm{M}$ and PC3, respectively; in the $85 \%$ BFS samples, they were $10 \%$ and $15 \%$; and finally, in the $70 \%$ BFS samples, the drops were $9 \%$ and $16 \%$. These reductions were related to an increase of the entrained or entrapped air in the mortar, as observed previously by [31], or the stability behaviour of admixtures in highly alkali media [30]. The loss of the compressive strength was somewhat greater in mortars with the polycarboxylate admixture.

\subsubsection{Porosity}

Figure 6 shows the pore size distribution and total porosity measured by MIP method at 28 days. The total porosities of the $100 \%$ BFS, 85\% BFS and 70\% BPS mortars were 12.6, 9.4 and $11.3 \%$ respectively. The three samples exhibited the same two most-probable pores with a size of around 7-8 $\mathrm{nm}$ and 1-2.5 $\mu \mathrm{m}$. The incorporation of fly ash in the formulations induced a reduction in total porosity. The fly ash may be acting as a filler due to the low reactivity at room temperature [52], refining the pore structure of the $85 \%$ BFS and $70 \%$ BFS samples. However, there was no clear trend between the values. Lee et al. [19] also observed that, as the amount of slag increased, the total porosity increased, since the pore volume in the region of the mesopores $(2-50 \mathrm{~nm})$ was greater, as can be seen in Figure 6 .

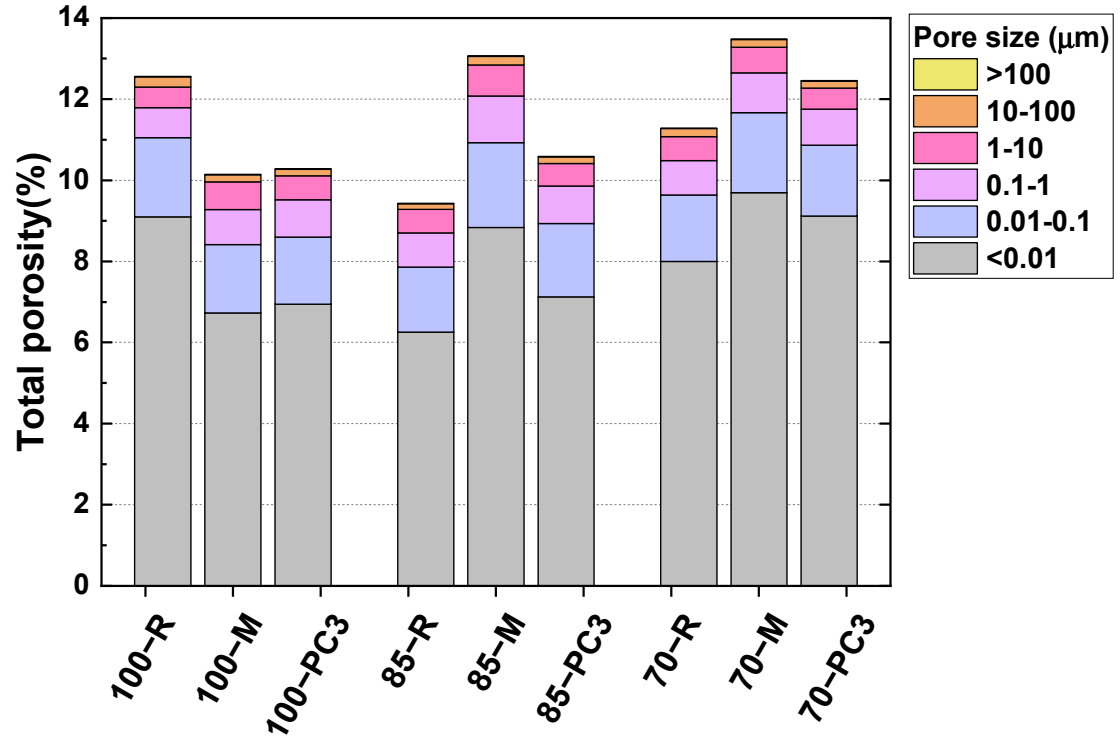

Figure 6. Pore size distribution and total porosity of alkali-activated slag/fly ash mortars in the absence and presence of M and PC3 admixtures at 28 days.

Two different behaviours were observed in the pore size distribution and total porosity of the three alkali-activated slag/fly ash mortars with M and PC3. The total porosity decreased for the $100 \%$ BFS mortars in the presence of both admixtures, with a lower percentage of gel pores $($ size $<0.01 \mu \mathrm{m})$. Their presence improved the mobility of the particles, leading to better packing. For the $85 \%$ and $70 \%$ BFS mortars, the entrained air increased and the total porosity increased although it was higher for those with $M$. However, a refinement in porosity was detected with a rise in porosity of a smaller size. Therefore, the nature and dosage of the raw materials that constituted the alkali-activated cement seemed to condition how the additives affect porosity.

In light of the results, M and PC3 improved the workability of the three alkali-activated slag/fly ash blends for $2 \mathrm{~h}$, even the presence of $\mathrm{M}$ admixture increased the early mechanical strengths due to their superplasticizer function. However, their impact on the hardened properties at 28 days was negative, thus reducing the compressive strengths and increasing the total porosity. 


\section{Conclusions}

This study investigated the fresh and hardened properties of three alkali-activated slag/fly ash mixtures (100/0, 85/15 and 70/30) with five superplasticisers (vinyl copolymer, melamine and three polycarboxylates). The following conclusive statements hold:

A higher proportion of fly ash in the alkali-activated pastes increased workability over time and retarded setting due to its smooth spherical shape and low reactivity at room temperature. In addition, a retarded reaction kinetic and a decrease in mechanical strengths were observed because a lower calcium content was provided to the medium and a decelerated formation of C-S-H gel took place. Total porosities decreased with the incorporation of fly ash, so it may have acted as a filler.

The presence of melamine and PC3 polycarboxylate admixtures in the three alkaliactivated slag/fly ashes pastes provided greater fluidity. Vinyl copolymer and polycarboxylates admixtures underwent alkaline hydrolysis in this sodium silicate medium. However, PC3 admixture exerted its plasticising function more effectively due to the presence of very long chains in its structure.

The presence of M and PC3 retarded the initial alkaline activation because they were absorbed onto the slag and ash grains thereby improving the workability of the three pastes. At 2 days, the compressive strengths were maintained or increased in the presence of $\mathrm{M}$ and PC3 admixtures, so that a good dispersion of these grains led to dense and homogenous mortars. However, these values decreased at long curing times due to the entrained or entrapped air in the mortar, which was also reflected in an increase in the total porosity of the $85 \%$ BFS and $70 \%$ BFS mortars.

Author Contributions: Conceptualization, M.C.; methodology, M.C. and M.J.d.H.; formal analysis, M.J.d.H.; investigation, M.J.d.H.; resources, M.J.d.H. and M.C.; data curation, M.C. and M.J.d.H.; writing—original draft preparation, M.J.d.H.; writing—review and editing, M.C.; visualization, M.C.; supervision, M.C.; project administration, M.C.; funding acquisition, M.C. All authors have read and agreed to the published version of the manuscript.

Funding: This research was funded by Ayudas de Atracción de Talento Investigador de la Comunidad Autónoma de Madrid, grant number 2019-T1/AMB-13672. This work was carried out within the framework of the IRINEMA project.

Acknowledgments: Thanks to companies Sika and Calumite Ibérica for supplying the admixtures and blast furnace slag for the study.

Conflicts of Interest: The authors declare no conflict of interest.

\section{References}

1. Luukkonen, T.; Abdollahnejad, Z.; Yliniemi, J.; Kinnunen, P.; Illikainen, M. One-part alkali-activated materials: A review. Cem. Concr. Res. 2018, 103, 21-34. [CrossRef]

2. Yousefi Oderji, S.; Chen, B.; Ahmad, M.R.; Shah, S.F.A. Fresh and hardened properties of one-part fly ash-based geopolymer binders cured at room temperature: Effect of slag and alkali activators. J. Clean. Prod. 2019, 225, 1-10. [CrossRef]

3. Deir, E.; Gebregziabiher, B.S.; Peethamparan, S. Influence of starting material on the early age hydration kinetics, microstructure and composition of binding gel in alkali activated binder systems. Cem. Concr. Compos. 2014, 48, 108-117. [CrossRef]

4. Criado, M.; Aperador, W.; Sobrados, I. Microstructural and mechanical properties of alkali activated Colombian raw materials. Materials 2016, 9, 158. [CrossRef] [PubMed]

5. Hojati, M.; Radlińska, A. Shrinkage and strength development of alkali-activated fly ash-slag binary cements. Constr. Build. Mater. 2017, 150, 808-816. [CrossRef]

6. Roy, D.M.; Jiang, W.; Silsbee, M.R. Chloride diffusion in ordinary, blended, and alkali-activated cement pastes and its relation to other properties. Cem. Concr. Res. 2000, 30, 1879-1884. [CrossRef]

7. Brough, A.R.; Atkinson, A. Sodium silicate-based, alkali-activated slag mortars-Part I. Strength, hydration and microstructure. Cem. Concr. Res. 2002, 32, 865-879. [CrossRef]

8. Karahan, O.; Yakupoglu, A. Resistance of alkali-activated slag mortar to abrasion and fire. Adv. Cem. Res. 2011, 23, 289-297. [CrossRef]

9. Rostami, H.; Brendley, W. Alkali ash material: A novel fly ash-based cement. Environ. Sci. Technol. 2003, 37, 3454-3457. [CrossRef] [PubMed]

10. Bakharev, T. Resistance of geopolymer materials to acid attack. Cem. Concr. Res. 2005, 35, 658-670. [CrossRef] 
11. Škvára, F.; Jílek, T.; Kopecký, L. Geopolymer materials based on fly ash. Ceram.-Silik 2005, 49, 195-204.

12. Fernandez-Jimenez, A.; García-Lodeiro, I.; Palomo, A. Durability of alkali-activated fly ash cementitious materials. J. Mater. Sci. 2007, 42, 3055-3065. [CrossRef]

13. Martin, A.; Pastor, J.Y.; Palomo, A.; Fernández Jiménez, A. Mechanical behaviour at high temperature of alkali-activated aluminosilicates (geopolymers). Constr. Build. Mater. 2015, 93, 1188-1196. [CrossRef]

14. Ismail, I.; Bernal, S.A.; Provis, J.L.; San Nicolas, R.; Hamdan, S.; Van Deventer, J.S.J. Modification of phase evolution in alkaliactivated blast furnace slag by the incorporation of fly ash. Cem. Concr. Compos. 2014, 45, 125-135. [CrossRef]

15. Saha, S.; Rajasekaran, C. Enhancement of the properties of fly ash based geopolymer paste by incorporating ground granulated blast furnace slag. Constr. Build. Mater. 2017, 146, 615-620. [CrossRef]

16. Ismail, I.; Bernal, S.A.; Provis, J.L.; San Nicolas, R.; Brice, D.G.; Kilcullen, A.R.; Hamdan, S.; Van Deventer, J.S.J. Influence of fly ash on the water and chloride permeability of alkali-activated slag mortars and concretes. Constr. Build. Mater. 2013, 48, 1187-1201. [CrossRef]

17. Chang, J.J. A study on the setting characteristics of sodium silicate-activated slag pastes. Cem. Concr. Res. 2003, 33, 1005-1011. [CrossRef]

18. Kumar, S.; Kumar, R.; Mehrotra, S.P. Influence of granulated blast furnace slag on the reaction, structure and properties of fly ash based geopolymer. J. Mater. Sci. 2010, 45, 607-615. [CrossRef]

19. Lee, N.K.; Lee, H.K. Setting and mechanical properties of alkali-activated fly ash/slag concrete manufactured at room temperature Constr. Build. Mater. 2013, 47, 1201-1209. [CrossRef]

20. Blaakmer, J. Diabind: An alkali-activated slag fly ash binder for acid-resistant concrete. Fuel Energy Abstr. 1995, 5, 336. [CrossRef]

21. Palomo, Á.; Fernández-jiménez, A.; López-hombrados, C.; Lleyda, J.L. Railway sleepers made of alkali activated fly ash concrete. Rev. Ing. Constr. 2007, 22, 75-80. [CrossRef]

22. Van Deventer, J.S.J.; Provis, J.L.; Duxson, P. Technical and commercial progress in the adoption of geopolymer cement. Miner. Eng. 2012, 29, 89-104. [CrossRef]

23. Provis, J.L. Demonstration Projects and Applications in Building and Civil Infrastructure. In Alkali Activated Materials. RILEM State-of-the-Art Reports; Provis, J.L., Van Deventer, J.S.J., Eds.; Springer: Dordrecht, The Netherlands, 2014; Volume 13, ISBN 9789400776722.

24. Shojaei, M.; Behfarnia, K.; Mohebi, R. Application of alkali-activated slag concrete in railway sleepers. J. Mater. Des. 2015, 69, 89-95. [CrossRef]

25. Burgos-Montes, O.; Palacios, M.; Rivilla, P.; Puertas, F. Compatibility between superplasticizer admixtures and cements with mineral additions. Constr. Build. Mater. 2012, 31, 300-309. [CrossRef]

26. Tong, S.; Yuqi, Z.; Qiang, W. Recent advances in chemical admixtures for improving the workability of alkali-activated slag-based material systems. Constr. Build. Mater. 2021, 272, 121647. [CrossRef]

27. Palacios, M.; Puertas, F. Stability of superplasticiser and shrinkage-reducing admixtures in high basic media. Mater. Constr. 2004, 54, 65-86.

28. Palacios, M.; Puertas, F. Effect of superplasticizer and shrinkage-reducing admixtures on alkali-activated slag pastes and mortars Cem. Concr. Res. 2005, 35, 1358-1367. [CrossRef]

29. Keulen, A.; Yu, Q.L.; Zhang, S.; Grünewald, S. Effect of admixture on the pore structure refinement and enhanced performance of alkali-activated fly ash-slag concrete. Constr. Build. Mater. 2018, 162, 27-36. [CrossRef]

30. Alrefaei, Y.; Wang, Y.S.; Dai, J.G. The effectiveness of different superplasticizers in ambient cured one-part alkali activated pastes Cem. Concr. Compos. 2019, 97, 166-174. [CrossRef]

31. Jang, J.G.; Lee, N.K.; Lee, H.K. Fresh and hardened properties of alkali-activated fly ash/slag pastes with superplasticizers. Constr. Build. Mater. 2014, 50, 169-176. [CrossRef]

32. Laskar, S.M.; Talukdar, S. Preparation and tests for workability, compressive and bond strength of ultra-fine slag based geopolymer as concrete repairing agent. Constr. Build. Mater. 2017, 154, 176-190. [CrossRef]

33. Namitha, S.; Muhammed Nabil, K.; Mohammed Rafeeque, N.V.; Sundhar, R.; Raju, T.; Ramaswamy, K.P. A study on the setting and flow behaviour of alkali activated slag/fly ash composites in ambient condition. IOP Conf. Ser. Mater. Sci. Eng. 2020, 989, 012004. [CrossRef]

34. Raju, T.; Ramaswamy, K.P.; Saraswathy, B. Effects of slag and superplasticizers on alkali activated geopolymer paste. IOP Conf. Ser. Earth Environ. Sci. 2020, 491, 012042. [CrossRef]

35. Pourhakkak, P.; Taghizadeh, A.; Taghizadeh, M.; Ghaedi, M.; Haghdoust, S. Fundamentals of Adsorption Technology, 1st ed.; Elsevier Ltd.: Amsterdam, The Netherlands, 2021; Volume 33, ISBN 9780128188057.

36. Criado, M.; Walkley, B.; Ke, X.; Provis, J.L.; Bernal, S.A. Slag and activator chemistry control the reaction kinetics of sodium metasilicate-activated slag cements. Sustainability 2018, 10, 4709. [CrossRef]

37. Provis, J.L. Geopolymers Structures Processing Properties and Industrial Applications; Provis, J.L., Van Deventer, J.S.J., Eds.; Wood Publishing: Cambridge, UK, 2009; pp. 50-71, ISBN 9781845692636.

38. Provis, J.L.; Bernal, S.A. Geopolymers and related alkali-activated materials. Annu. Rev. Mater. Res. 2014, 44, 299-327. [CrossRef]

39. Provis, J.L. Geopolymers and other alkali activated materials: Why, how, and what? Mater. Struct. 2014, 47, 11-25. [CrossRef]

40. Tan, Z.; Bernal, S.A.; Provis, J.L. Reproducible mini-slump test procedure for measuring the yield stress of cementitious pastes. Mater. Struct. Constr. 2017, 50, 235. [CrossRef] 
41. UNE. EN. 196-3. Métodos de Ensayos de Cementos. Parte 3: Determinación del Tiempo de Fraguado y de la Estabilidad de Volumen; AENOR: Madrid, Spain, 2005.

42. UNE. EN. 196-1. Métodos de Ensayos de Cementos. Parte 1: Determinación de Resistencias Mecánicas; AENOR: Madrid, Spain, 2005.

43. Fang, G.; Bahrami, H.; Zhang, M. Mechanisms of autogenous shrinkage of alkali-activated fly ash-slag pastes cured at ambient temperature within 24 h. Constr. Build. Mater. 2018, 171, 377-387. [CrossRef]

44. Nedunuri, A.S.S.S.; Muhammad, S. Fundamental understanding of the setting behaviour of the alkali activated binders based on ground granulated blast furnace slag and fly ash. Constr. Build. Mater. 2021, 291, 123243. [CrossRef]

45. Vikas, G.; Rao, T.D.G. Setting Time, Workability and Strength Properties of Alkali Activated Fly Ash and Slag Based Geopolymer Concrete Activated with High Silica Modulus Water Glass. Iran. J. Sci. Technol. Trans. Civ. Eng. 2021, 45, 1483-1492. [CrossRef]

46. Criado, M.; Palomo, A.; Fernández-Jiménez, A.; Banfill, P.F.G. Alkali activated fly ash: Effect of admixtures on paste rheology. Rheol. Acta 2009, 48, 447-455. [CrossRef]

47. Alrefaei, Y.; Wang, Y.S.; Dai, J.G. Effect of mixing method on the performance of alkali-activated fly ash/slag pastes along with polycarboxylate admixture. Cem. Concr. Compos. 2021, 117, 103917. [CrossRef]

48. Li, S.; Zhang, J.; Li, Z.; Gao, Y.; Liu, C. Feasibility study of red mud-blast furnace slag based geopolymeric grouting material: Effect of superplasticizers. Constr. Build. Mater. 2021, 267, 120910. [CrossRef]

49. Dai, X.; Aydin, S.; Yardimci, M.Y.; Lesage, K.; de Schutter, G. Influence of water to binder ratio on the rheology and structural Build-up of Alkali-Activated Slag/Fly ash mixtures. Constr. Build. Mater. 2020, 264, 120253. [CrossRef]

50. Gao, X.; Yu, Q.L.; Brouwers, H.J.H. Reaction kinetics, gel character and strength of ambient temperature cured alkali activated slag-fly ash blends. Constr. Build. Mater. 2015, 80, 105-115. [CrossRef]

51. Chithiraputhiran, S.; Neithalath, N. Isothermal reaction kinetics and temperature dependence of alkali activation of slag, fly ash and their blends. Constr. Build. Mater. 2013, 45, 233-242. [CrossRef]

52. Winnefeld, F.; Leemann, A.; Lucuk, M.; Svoboda, P.; Neuroth, M. Assessment of phase formation in alkali activated low and high calcium fly ashes in building materials. Constr. Build. Mater. 2010, 24, 1086-1093. [CrossRef] 